\title{
Physiological Traits Determining Yield Tolerance of Wheat to Foliar Diseases
}

\author{
F. van den Berg,† N. D. Paveley, I. J. Bingham, and F. van den Bosch
}

First author: Agriculture and Horticulture Department, Fera Science Ltd., Sand Hutton, York, YO41 1LZ, United Kingdom; second author: Plant Pathology Department, ADAS, High Mowthorpe, Duggleby, Malton, North Yorkshire, YO17 8BP, United Kingdom; third author: Crop \& Soils Systems, Scotland's Rural College, Kings Buildings, West Mains Road, Edinburgh EH9 3JG, United Kingdom; and fourth author: Computational and Systems Biology, Rothamsted Research, Harpenden, Hertfordshire, AL5 2JQ, United Kingdom. Accepted for publication 20 July 2017.

\begin{abstract}
Tolerance is defined as the ability of one cultivar to yield more than another cultivar under similar disease severity. If both cultivars suffer an equal loss in healthy (green) leaf area duration (HAD) over the grain filling period due to disease presence, then the yield loss per unit HAD loss is smaller for a more tolerant cultivar. Little is understood of what physiological and developmental traits of cultivars determine disease tolerance. In this study, we use a mathematical model of wheat to investigate the effect of a wide range of wheat phenotypes on tolerance. During the phase from stem extension to anthesis, the model calculates the assimilate source and sink potential, allowing for dynamic changes to the source-sink balance by partitioning assimilates between ear development and storage of watersoluble carbon (WSC) reserves, according to assimilate availability. To quantify tolerance, rates of epidemic progress were varied on each phenotype, leading to different levels of HAD loss during the postanthesis, grain-filling period. Model outputs show that the main determinant of tolerance is the
\end{abstract}

ABSTRACT total amount of assimilate produced per grain during the rapid grain-fill period, leading to a strong positive correlation between HAD per grain and tolerance. Reductions in traits that affect carbon assimilation rate and increases in traits that determine the amount of structural biomass in the plant increase disease tolerance through their associated reduction in number of grains per ear. Some of the most influential traits are the canopy green area index, carbon use efficiency, and leaf specific weight. Increased WSC accumulation can either increase or decrease tolerance. Furthermore, a cultivar is shown to be maximally tolerant when a crop is able to just fill its total sink size in the presence of disease. The model has identified influential functional traits and established that their associations with tolerance have a mechanistic basis.

Additional keywords: Septoria tritici blotch, stem reserves, Triticum aestivum, Zymoseptoria tritici.
Minimizing losses from disease requires the development of integrated and sustainable approaches to disease management that couple techniques to maximize plant defense (disease tolerance and resistance) with appropriate methods of chemical and cultural control. Cultivars that are tolerant to disease have higher yields than intolerant cultivars at the same disease severity (Parker et al. 2004). There is a clear relationship between measures of disease severity such as the area under the disease progress curve (AUDPC) and yield, whereby shallow slopes represent little yield loss per unit disease increase and, hence, a high disease tolerance. However, the use of AUDPC to measure tolerance has the clear disadvantage that, especially near the end of the growing season, it is difficult to distinguish between diseased and senesced leaf tissues. AUDPC is also related to the healthy (green) area duration (HAD) of a crop and HAD, in turn, is related to yield. A measure of tolerance based on HAD which has proven useful in experimental studies for foliar wheat diseases such as Zymoseptoria tritici is yield loss per unit loss in HAD of the crop canopy over the grain-filling period (Foulkes et al. 2006; Parker et al. 2004). HAD is hereby quantified as the healthy area index of the crop canopy, integrated over time, as defined by Waggoner and Berger (1987). Yield loss per unit HAD loss is smaller for more tolerant cultivars. This metric of tolerance can be expressed as the slope of the straight line of yield (tons per hectare) on HAD when there is a range of disease severities leading to a range of HAD values (Fig. 1). Cultivars with smaller slopes are classed as more tolerant. Waggoner and Berger (1987) described why disease-induced

†Corresponding author: F. van den Berg; E-mail: Femke.vandenberg@fera.co.uk

*The $\boldsymbol{e}$-Xtra logo stands for "electronic extra" and indicates that four supplementary files are published online.

(C) 2017 The American Phytopathological Society
HAD loss can be more predictive of yield loss than the more usual use of integrals of symptom area such as AUDPC. The latter are generally based on relative measures of disease severity (i.e., percentages or fractions of leaf surface occupied by lesions) which, unlike HAD, do not take into account the amount of green canopy area that remains. Parker et al. (2004) showed that, for Z . tritici, tolerance was indeed better quantified based on HAD loss than AUDPC.

Any single metric used to quantify tolerance (Bingham et al. 2009) will, however, inevitably be a simple summary of complex underlying processes and relationships. In this case, yield loss per unit HAD is the result of the complex and, often, nonlinear interactions by which crop development and canopy characteristics affect the crop's response to disease-induced changes in light capture, and assimilate production, allocation, and grain filling. Our model considers these complex mechanistic interactions to study how phenotypic traits and the dynamics of underlying variables affect the relationship of yield loss per unit HAD loss, as measured in the field.

Note that we distinguish here between tolerance and partial resistance, whereas the former is often used loosely in the literature as a synonym for the latter. The difference can be illustrated from Figure 1. Tolerance is expressed as a smaller slope of the yield-HAD loss relationship, resulting in a reduced yield loss for any given diseaseinduced HAD loss. Resistance is expressed through a reduction in disease severity, resulting in a smaller disease-induced loss of HAD. For any given size and duration of crop canopy (and, hence, HAD), in the absence of disease, a more resistant cultivar will be further to the right along the $\mathrm{x}$-axis compared with a more susceptible cultivar.

Progress with breeding cultivars for tolerance is hindered by lack of understanding about the traits and physiological processes that determine tolerance. Tolerance is believed to be associated with a high HAD per unit grain number, suggesting that plants for which source capacity is in excess of sink capacity are more tolerant of disease (Bingham et al. 2009). However, source and sink capacities 
are interrelated and are each determined by a number of physiological traits (Sinclair and Jamieson 2006). Thus, insight into the effect of physiological traits on source and sink dynamics, and how these feed through to tolerance, is needed to guide breeding.

The methods used to determine tolerance in the field are labor intensive, which may explain why few experimental studies (Foulkes et al. 2006; Parker et al. 2004) have been published comparing tolerance values across a range of cultivars or near-isogenic lines. Reliable guidance to plant breeders depends on being able to identify correlations between crop traits and tolerance that are a result of true mechanistic links. In field experiments, some correlations might arise by chance or because of correlations between traits (due to genetic linkage or concurrent selection in breeding programs). Such spurious correlations can be confirmed or refuted in mathematical models because they allow traits to be varied independently. Although HAD per grain was strongly correlated with tolerance in the experiments of Foulkes et al. (2006), it is not clear which underlying physiological traits drive this correlation. A mechanistic rationale is needed to add confidence that the relationship is causal. Furthermore, because HAD per grain is a compound variable (HAD combines green canopy size and duration), it is important to establish which crop characteristics and physiological processes are most influential. Therefore, the study presented here uses a mathematical model to identify and understand which traits determine the level of disease tolerance observed in wheat (Triticum aestivum L.).

Madden and Nutter (1995) discuss a wide range of models describing the relationship between yield and different injury mechanisms, including models that provide a detailed description of the spatial and temporal dynamics of the disease. However, most of these models use a rather simple description of the development and growth of the ear and its grain. Others do not keep track of the accumulation of reserves of water-soluble carbohydrate (WSC) in the stem, despite the fact that these dynamics strongly influence the source-sink balance, which is believed to be a major effector of tolerance (Sinclair and Jamieson 2006). The same is true for the crop growth models that have been developed to support plant breeding (Beasse et al. 2000; Bingham and Topp 2009; Carretero et al. 2010). In this article, we describe a new model that encompasses the physiological processes deemed important for disease tolerance, without making the model overly complex and hard to parameterize.

The work addresses the following questions with respect to Septoria tritici blotch, the major foliar disease of wheat in cool temperate cropping systems:

- What physiological and developmental crop traits determine tolerance?

- What trait combination makes a cultivar maximally tolerant?

- Do the correlations between traits and tolerance reported in the experimental literature have a mechanistic rationale or are they likely to be spurious correlations?

\section{MATERIALS AND METHODS}

Model development. This section describes the biological processes in the model. The model equations, parameter derivation, and trait value ranges are provided in Supporting Information SI1. A graphical representation of the model is given in Figure 2, whereas Table 1 highlights which plant traits are considered to be subject to targeted breeding and, therefore, will be varied within the model simulations.

Assumptions. The model tracks plant development and growth, and disease progress, across a crop growing season. The Decimal Code system for wheat growth stages (GS) is described by Zadoks et al. (1974). Model calculations start at the onset of stem extension (GS31) because yield components affected by Septoria tritici blotch are those which are determined after the start of stem extension.

Many tillers are aborted between GS31 and GS61 (SylvesterBradley et al. 2008). More recently developed tillers (i.e., those with the highest probability of being aborted after GS31) tend to be small and located at the bottom of the canopy. These tillers are unlikely to interfere significantly with light interception of the leaf tissues of the main shoot. Furthermore, ear numbers per square meter is a yield component seldom affected by Septoria tritici blotch in northern Europe (Robert et al. 2004). Therefore, tiller abortion is not explicitly modeled. In a well-established crop, grown at typical (commercial) plant population densities, the number of ears produced per plant tends to be small (main shoot ear plus two primary tiller ears) and the synchrony in flowering between main shoot and first and second tillers tends to be high. Therefore, all tillers are modeled as being at the same growth stage, whereby the shoot density is represented by the number of fertile ears per square meter.

The dynamics and quantification of assimilate accumulation are accounted for on the basis of an individual shoot. However, to enable the model to represent a crop as a population of shoots at a field scale, light interception by an individual shoot is based on the leaf area index of the crop (i.e., per unit ground area); thus, intershoot competition for light is accounted for.

Crop development. The model tracks the green area index (GAI) of individual leaf layers (lamina and sheath), representing leaf growth and natural senescence. Leaf growth is described by a monomolecular growth function (Thornley and Johnson 1990). Each leaf has a specific leaf longevity related to its size, after which leaf senescence commences (Supporting Information SI2).

Z. tritici is a hemibiotrophic foliar pathogen infecting wheat leaves and causing Septoria tritici blotch. The effect of $Z$. tritici lesions is to reduce the green leaf area, thus reducing the photosynthetic capacity of the crop canopy (Paveley et al. 2012). Necrotic lesions intercept solar radiation but are not photosynthetically active (Robert et al. 2006). The epidemic progress on each leaf layer is modeled according to a logistic equation, which provides an accurate presentation of the progress of Septoria tritici blotch under a range of conditions (Paveley et al. 2000). It is assumed that diseased and senesced tissues (i.e., infectious and postinfectious) no longer contribute to photosynthesis (Robert et al. 2006).

Biomass accumulation through photosynthesis. The mean irradiance for a specific leaf layer is calculated using the Lambert-Beer relationship describing light interception (Thornley and Johnson 1990), whereby the light extinction coefficient represents both light transmission through the leaves and leaf angle. The average daily rate of gross photosynthesis is then calculated using the standard nonrectangular hyperbola (Johnson and Thornley 1984) and converted to total $\mathrm{CO}_{2}$ fixed per shoot per day. Subtracting the carbon that is lost to maintenance and growth respiration

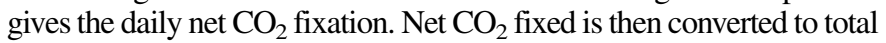

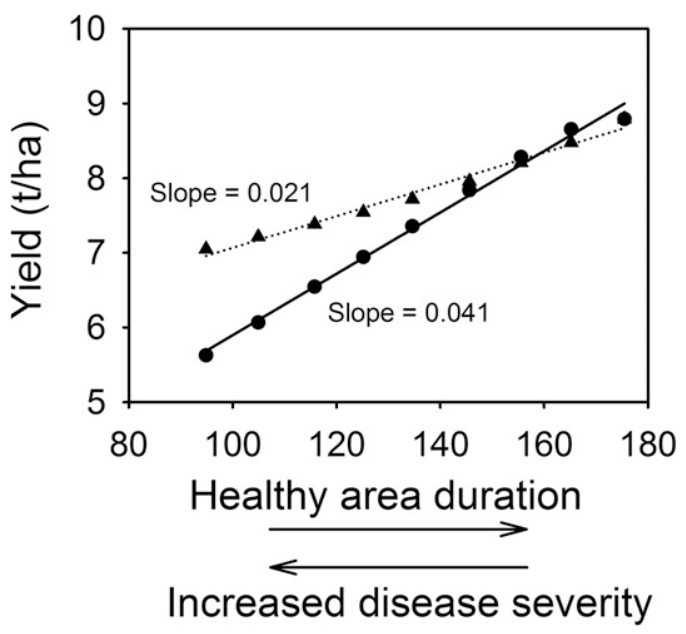

Fig. 1. Linear regression through simulated data of yield on healthy area duration (HAD) (green tissue area per unit ground area integrated over time). The slope of the regression line is a measure for tolerance, whereby smaller slopes denote a more tolerant crop. The dots and solid line are for Mercia and the triangles and dotted line represent a more tolerant cultivar. Note that a decrease in HAD is the result of increased disease severity. 
C fixed per shoot per day and, finally, to dry matter (DM) accumulated per shoot per day (Fig. 2A).

Preanthesis biomass partitioning. The total DM biomass accumulated per shoot from GS31 to anthesis (GS61) is first partitioned to plant leaves, structural stem, and roots according to organ sizes and specific weights (Fig. 2B). It is assumed that total biomass accumulation is always sufficient to meet these demands; otherwise, plants are not viable. Subsequently, the remainder of the biomass accumulated preanthesis is partitioned to either ear growth or stem reserves. Few experimental data exist on what drives this partitioning and how the assimilates are split between ear growth and building up stem reserves. Hence, this part of the model is necessarily of a descriptive nature rather than mechanistic. There is, however, evidence that ear or grain growth may be maintained over that of stem and leaf structural growth when conditions are limiting. For example, the harvest index of cereals (barley) is increased by nitrogen deficiency because ear and grain growth is maintained relatively more than stem and leaf growth (Bingham et al. 2012). Furthermore, early postanthesis shading of barley reduces stem WSC concentrations but not soluble sugar concentration in developing grain

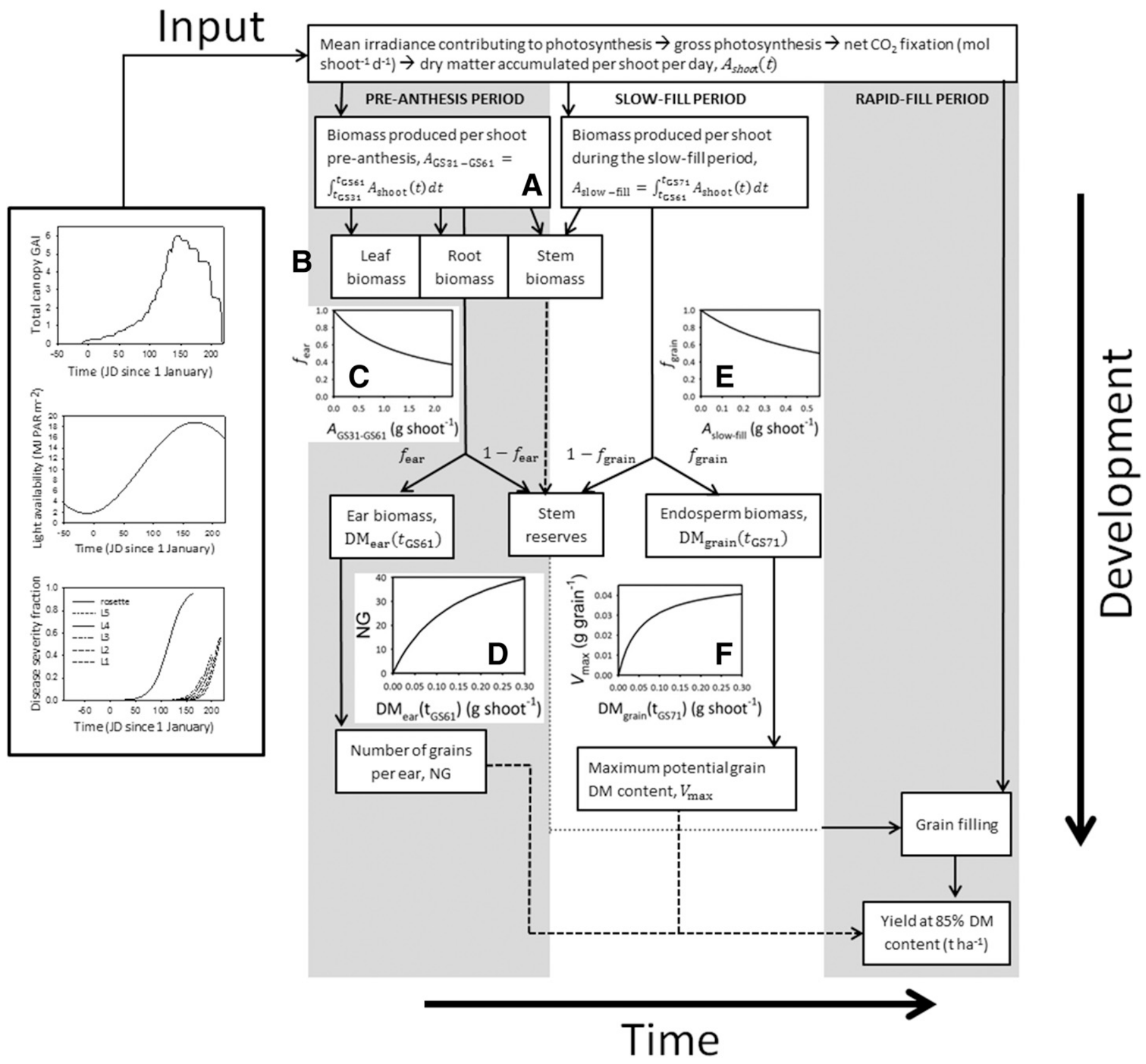

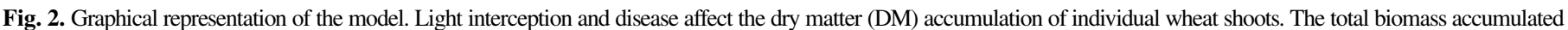

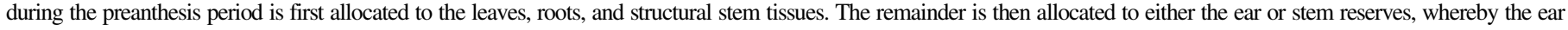

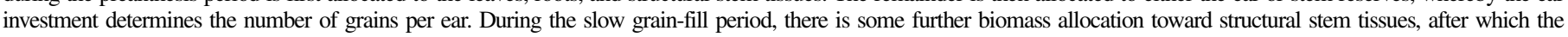

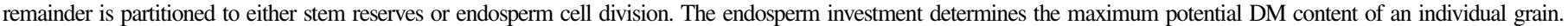

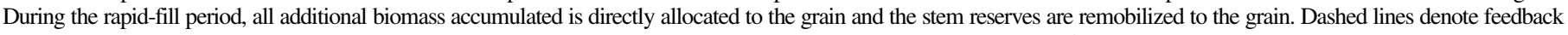

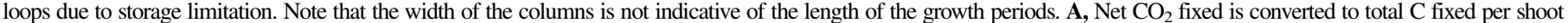

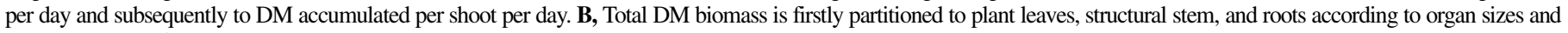

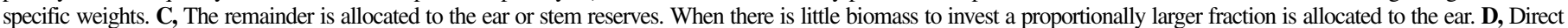

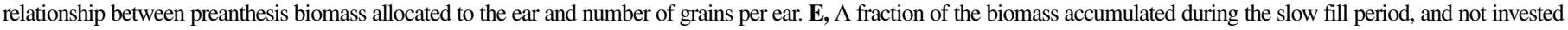

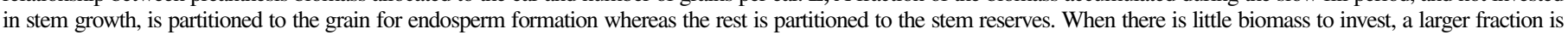

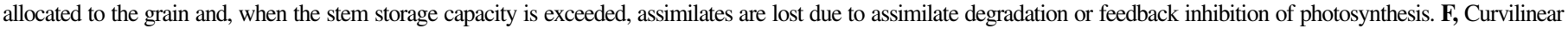
relationship between the DM allocation to an individual grain during the slow-fill period and the maximum potential grain DM content of the grain. 
(S. P. Kennedy, unpublished data). Hence, we assume that the fraction that is partitioned to the ear is a function of the total biomass accumulated preanthesis such that, when there is little biomass to invest, a proportionally larger fraction is allocated to the ear; whereas, when there is a lot of biomass to invest, a proportionally larger fraction is allocated to the stem reserves (Fig. 2C). All remaining biomass is partitioned to the stem as WSC for storage. If the total amount of WSC partitioned to the stem reserves exceeds the stem storage capacity, the excess is lost due to assimilate degradation or a temporary feedback inhibition of photosynthesis. Additionally, it is assumed that increased stem heights lead to a relatively higher assimilate pull from the stem because Clarke et al. (2012) showed that partitioning to the ear decreases nonlinearly with an increased stem height.

Number of grains per ear. If a floret does not accumulate sufficient biomass, it will not reach the development stage (anther initials in full development) required for successful fertilization, leading to the abortion of the floret (Bancal 2008; González et al. 2011). These processes are summarized by modeling a direct relationship between preanthesis biomass allocated to the ear and number of grains per ear (Fig. 2D).

Postanthesis biomass partitioning. The leaves and ear are now fully developed and all further biomass accumulated is partitioned to structural stem biomass, the stem reserves, and grain expansion or filling. The postanthesis period is split into two distinct periods: the slow fill and rapid grain-fill periods (Bingham et al. 2007b; Xie et al. 2015).

The slow-fill period takes, on average, 2 to 3 weeks. There is a continued allocation of assimilates to the stem reserves during this period (Schnyder 1993; Sylvester-Bradley et al. 2008). This continued allocation to the stem reserves is associated with some further stem growth (Sylvester-Bradley 1998a). A fraction of the biomass accumulated during the slow-fill period and not invested in stem growth is partitioned to the grain for endosperm formation, whereas the rest is partitioned to the stem reserves. As during the preanthesis period, it is assumed that, when there is little biomass to invest, a larger fraction is allocated to the grain (Fig. 2E) and, when the stem storage capacity is exceeded, "excess" assimilates are lost due to assimilate degradation or feedback inhibition of photosynthesis.

Assimilate supply during the slow-fill period determines the number of cell divisions that take place within the grain endosperm (Singh and Jenner 1984). The resultant number of cells, in turn, determines the capability of the grain to store water that can be replaced by DM during the rapid-fill period (Hasan et al. 2011). These dynamics are summarized by a curvilinear relationship between the DM allocation to an individual grain during the slow-fill period and the maximum potential grain DM content of the grain (Fig. 2F).

The final realized grain dry weight per ear at harvest is determined during the rapid-fill period. Any biomass accumulated during this period as a result of further light interception is directly invested in grain filling. At the same time, the stem reserves are remobilized to the grains. However, grain filling is limited by the potential grain DM content determined during the slow-fill period and the number of fertile grains set at anthesis. The resultant grain yield is expressed as tons per hectare at 85\% DM.

Regression analysis to estimate tolerance. For each disease pressure simulated, HAD (in square meter of green leaf area per square meter of ground area $\times$ duration in days) is calculated over the duration of the grain-fill period across the top four leaves. Rates of epidemic progress are varied, such that disease-induced HAD losses ranged between 5 and $50 \%$ under default conditions. The chosen HAD loss range is based on the observations that disease severities $>50 \%$ are rare and epidemics are unlikely to impact materially on yield for severities $<5 \%$. Our measure for tolerance, expressed as tons per hectare per $\mathrm{HAD}$, is then calculated as the slope of the yield-HAD relation (Fig. 1), whereby small slopes denote more tolerant crops. We then analyzed how changes in parameters representing underlying source and sink traits affect the slope of this relationship.

By the definition used here, a crop is more tolerant when disease presence results in a smaller yield loss per unit HAD lost to disease. Yield is the product of the crop's total sink size and the percentage of the total sink the crop is able to fill during the grain-fill period. This can be summarized by

$$
\begin{aligned}
(1 / \text { tolerance }) \propto & (\Delta \text { yield } / \Delta \mathrm{HAD}) \\
& =\Delta\{\text { total sink size } \times \\
& (\% \text { sink filled } / 100)\} / \Delta \mathrm{HAD}
\end{aligned}
$$

where $\Delta$ indicates the difference between a healthy and diseased crop. The equation shows that it is the balance between $\Delta$ total sink size, $\Delta \%$ sink filled, and $\triangle \mathrm{HAD}$ that determines the level of tolerance. A central question is whether one of these three factors is the key variable in explaining tolerance or whether they are all similarly important. Insight at that level can guide us to characterize the crop

\begin{tabular}{|c|c|c|c|}
\hline \multirow[b]{2}{*}{ Trait description } & \multirow[b]{2}{*}{ Units } & \multicolumn{2}{|c|}{ Trait } \\
\hline & & Value & Range \\
\hline Preanthesis period & Days & 59 & $51-65$ \\
\hline Slow-fill period & Days & 16 & $5-21$ \\
\hline Rapid-fill period & Days & 34 & $24-37$ \\
\hline Shoot density & Per square meter & 578 & $294-578$ \\
\hline Maximum canopy green area index & $\ldots$ & 6.03 & $3.26-7.51$ \\
\hline Carbon use efficiency & $\ldots$ & 0.79 & $0.62-0.79$ \\
\hline Light extinction coefficient & $\ldots$ & 0.53 & $0.37-0.58$ \\
\hline Maximum photosynthetic capacity & Moles of $\mathrm{CO}_{2}$ per square meter leaf per day & 1.83 & $1.28-2.07$ \\
\hline Fraction ear versus stem reserves investment & $\ldots$ & 0.48 & $0.37-0.49$ \\
\hline Maximum number of grains per ear & $\ldots$ & 59.30 & $57.37-97.44$ \\
\hline Fraction grain versus stem reserves investment & $\ldots$ & 0.55 & $0.50-0.59$ \\
\hline Maximum potential grain dry matter content & Grams & 0.048 & $0.040-0.056$ \\
\hline Leaf specific weight & Grams per square meter & 32 & $31.8-54.0$ \\
\hline Root mass & Grams per shoot & 0.17 & $0.11-0.17$ \\
\hline Stem specific weight & Grams per meter & 1.36 & $1.08-1.62$ \\
\hline Stem height at anthesis & Meters & 0.64 & $0.64-1.10$ \\
\hline Stem diameter & Meters & 0.0033 & $0.0032-0.0041$ \\
\hline Fractional stem thickness & & 0.35 & $0.33-0.38$ \\
\hline Stem storage efficiency & Grams per cubic meter & 287,075 & $220,341-353,087$ \\
\hline Stem reserves remobilization rate & Per day & 0.088 & $0.081-0.125$ \\
\hline $\begin{array}{l}\text { Leaf distribution (flag leaf area/area of top } \\
\text { five leaves) }\end{array}$ & $\ldots$ & 0.23 & $0.23-0.43$ \\
\hline
\end{tabular}
physiological processes that are most influential to tolerance.

TABLE 1. Description of the traits that could be subject to targeted breeding ${ }^{a}$

${ }^{a}$ All default model parameters are representative for Mercia wheat. The current trait ranges describe the current genotypic variability for each trait based on genotype means as found in the literature. 
The percentage of the sink that can be filled depends on the total amount of assimilate available for grain filling and the total sink size (number of grains per ear multiplied by the potential maximum grain volume); in other words

$\%$ sink filled $\propto\{(\mathrm{HAD}$ during grain fill

$$
\begin{aligned}
& + \text { WSC reserves }) / \\
& (\text { number of grains per ear } \\
& \times \text { potential maximum grain volume })\} \times 100
\end{aligned}
$$

The measure of $\%$ sink filled is a good indicator for the source-sink balance, whereby $100 \%$ sink filled indicates a fully sink-limited crop (i.e., yield is limited by sink capacity). The effect of a particular trait on tolerance is therefore determined by its relative effects on source and sink.

Model calibration and validation. The model was calibrated according to data obtained from the Home Grown Cereals Authority wheat growth guide (Sylvester-Bradley et al. 2008) and its underlying reports (Spink et al. 2000a; Spink et al. 2000b, 2004; Sylvester-Bradley 1998a,b,c). These data give the most comprehensive set of parameter estimates, based on many field experiments, for a single cultivar ('Mercia') within the published literature. Thus, Mercia is our benchmark cultivar. A literature search was performed to determine the current genotypic variability of plant traits (Table 1), representing the variability in these traits across different cultivars.

Some trait change correlations. Increases in maximum canopy GAI are simulated by increasing all leaf sizes by the same percentage. When the leaf area distribution is changed, the total canopy GAI is kept constant by reducing the total area of leaves 2 to 5 by the same amount that the flag leaf is increased.

Two sets of traits were treated as being closely related, because they are unlikely to be varied independently in practice. Changes to growth periods are assumed to be directly related to changes in canopy dynamics, whereby an increased preanthesis period is assumed to be associated with an equal percent increase in phyllochron length. An increased slow-fill or rapid-fill period goes paired with an increase in leaf longevity of the top five leaves by an equal number of days.

Model validation. We validated the model using three distinct approaches. First, we tested the model's power to predict yield and yield components by comparing model predictions with published data from five independent field experiments. This validation is reported in Supporting Information SI3 because it does not directly relate to tolerance but presents evidence for the validity of our model. Second, as a quantitative validation with respect to tolerance, the range of published tolerance values was compared with the range of tolerance values predicted by the model. Third, a qualitative validation was performed by comparing published and model-derived trends between plant traits and tolerance. None of the articles and data sets used within this validation exercise were used for model calibration.

Testing diverse parameter sets. We used Mercia as the default parameter set (Table 1), and studied the effect of changes in parameters relative to this default set. The question, then, was whether our conclusions would also hold for other parameter value sets. To test this, we simulated parameter sets by randomly selecting values from the ranges determined (Table 1). For each of these parameter sets, we first determined the yield of the crop. Because the aim was to identify trait combinations that will lead to improved disease tolerance but, at the same time, maintain acceptable yields, we only determined tolerance as described above for those parameter sets that lead to crop yields greater than or equal to Mercia: 9 tons per hectare in field crops, as reported by Sylvester-Bradley (1998c).

\section{RESULTS}

What physiological crop traits determine tolerance? The yield of a more tolerant plant is less strongly affected by disease presence than an intolerant plant. Therefore, we studied how trait changes affect certain source and sink components in the presence of the disease as compared with in the absence of disease (Fig. 3, individual lines). Trait changes leading to increased tolerance might then be identified by a smaller effect of disease on the source or sink components (the lines for disease absence and presence lie closer together, with the difference denoted by $\Delta$ ). Equation 1 shows that the level of tolerance experienced by a plant is determined by the balance between $\Delta$ total sink size, $\Delta \%$ sink filled, and $\Delta H A D$. In this section, we look at whether one of these three factors is the key variable in explaining tolerance.

Let's first consider the cases where a trait change has no effect on HAD and where, additionally, $\Delta \%$ sink filled $\neq 0$ (Fig. 3C, carbon use efficiency $>0.64$ ). For these cases, the results show that tolerance generally increases when $\Delta \%$ sink filled decreases and vice versa (Figs. 3A and 4A). There are a few exceptions to this finding, for a small part of the trait range for the maximum number of grains per ear and maximum potential grain volume (Fig. 4A). For trait changes that have an opposing effect on $\Delta$ total sink size and $\Delta \%$ sink filled, it was found that, in most cases, $\Delta \%$ sink filled determines the overall effect on tolerance (Figs. 3B and 5B; Supporting Information SI4, panel $\mathrm{B}$ in all figures). When trait changes also affect $\triangle \mathrm{HAD}$, such as for GAI in Figure 5 and traits with closed symbols in Figure 4A, the negative relation between $\Delta \%$ sink filled and tolerance is maintained for most traits (Fig. 4A), although the effect is less pronounced than in cases where the trait change does not affect $\triangle \mathrm{HAD}$ (Fig. 4A, open symbols). Only two traits, the durations of the preanthesis period and the rapid grain-fill period, show slightly different behavior.

Now, consider the case where the yield is fully sink limited (i.e., the plant is able to completely fill its available sink regardless of whether disease is present or not). In the figures, these cases are denoted by trait value ranges for which the \%sink filled is the same in the presence and absence of disease $(\Delta \%$ sink filled $=0$ and [\%sink filled $/ 100]=1$ in equation 1; Fig. 3C, carbon use efficiency $[\mathrm{CUE}]<0.64)$. In these extreme cases, we still detect an effect on tolerance despite $\Delta \%$ sink filled not being affected and, hence, in these cases, $\Delta$ total sink size and $\triangle \mathrm{HAD}$ control whether tolerance increases or decreases with a change in parameter (trait) value (Fig. 3).

For all trait ranges investigated, the change in total sink size is driven predominantly by the number of grains per ear (Fig. 4D). In combination with the finding that there is a direct correlation between $\Delta \%$ sink filled and tolerance, equation 2 shows that tolerance, therefore, is closely related to the total assimilate available per grain. The total assimilate available per grain is determined by both HAD and the WSC reserves. Although the results reveal a significant correlation between tolerance and HAD per grain (Fig. 4F), no clear trend between WSC reserves and tolerance can be identified (Fig. 4E).

For the traits CUE (Fig. 3), stem height at anthesis, stem diameter, and leaf specific weight, the tolerance curve has a clear maximum, which coincides with the trait value where $\Delta \%$ sink filled goes from being $>0$ to 0 . Thus, a prerequisite for maximal tolerance is that the source is just large enough to fill the sink in both the absence and presence of disease. Note, however, that the plots have been created by simulating a single disease severity and that the exact location of the optimum depends on the disease severity encountered.

Results comparison against experimental data. This section presents results for correlations between specific pairs of traits which have previously been reported as being associated in experimental data. The discussion cites the relevant literature and describes the extent to which the modeling results agree with or differ from the experimental evidence.

The model predicts that (i) an increase in the maximum number of grains per ear is negatively correlated to tolerance (Fig. 6A), (ii) flag leaf area relative to total leaf area (referred to as leaf distribution) and tolerance are positively correlated (Fig. 6B), (iii) reduced stem height leads to a strong reduction in tolerance (Fig. 6C), (iv) the maximum photosynthetic capacity $\left(P_{\max }^{0}\right)$ is weakly negatively correlated with 


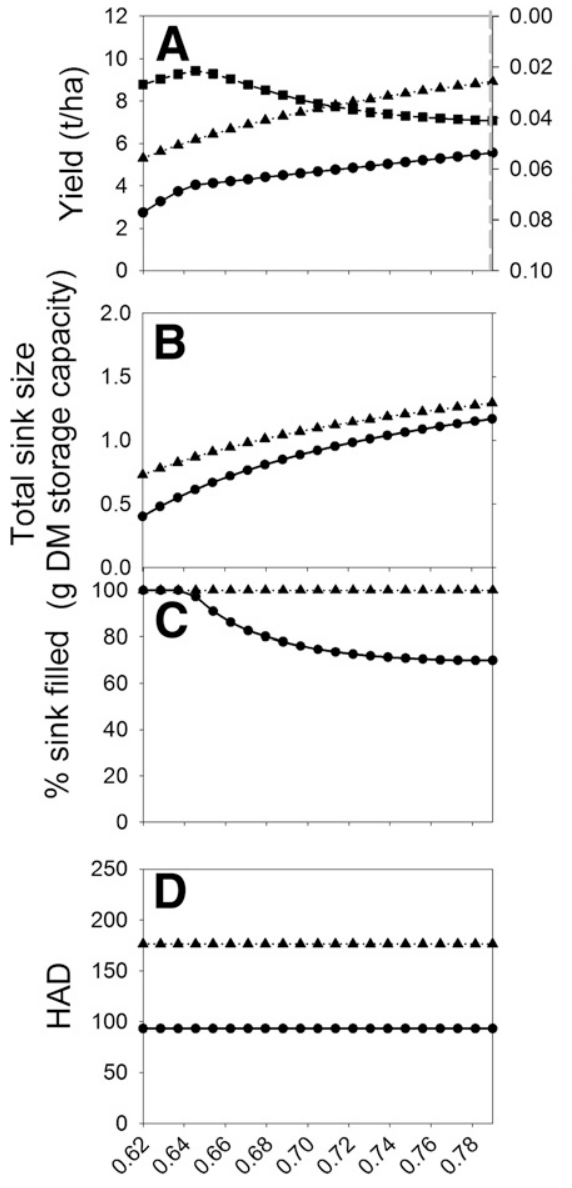

Carbon use efficiency
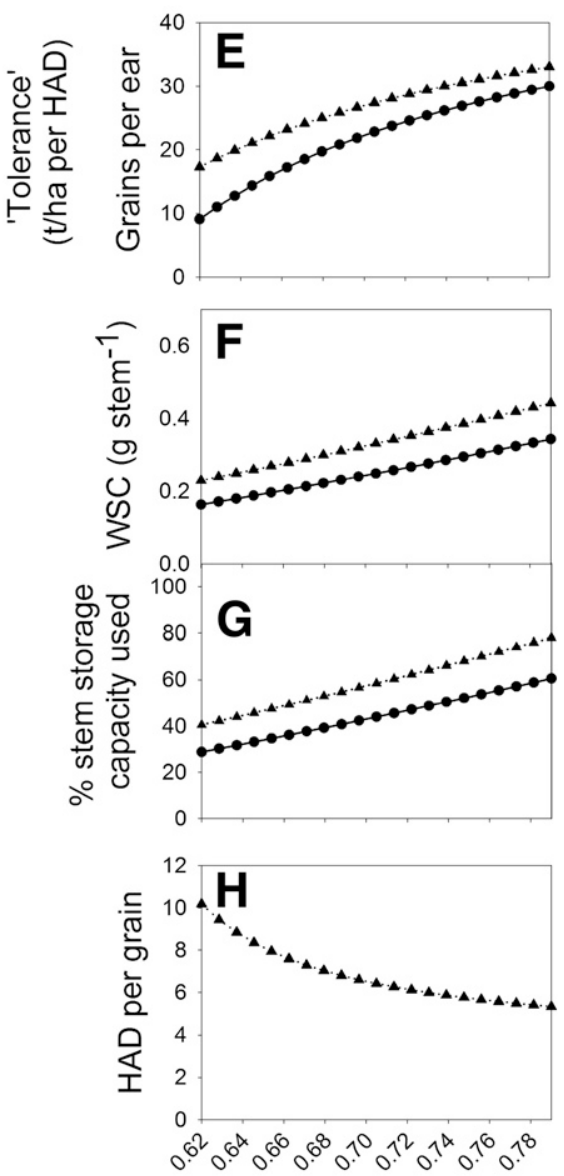

Carbon use efficiency

Fig. 3. Effect of changes in carbon use efficiency on disease tolerance. Trends in tolerance (A, squares) across the trait value range are explained according to the effects of the presence of a severe epidemic on four main components: A, yield; $\mathbf{B}$, total realized sink size; $\mathbf{C}$, percentage of total sink filled at the end of the rapidfill period; and $\mathbf{D}$, healthy area duration (HAD). The same trait change affects $\mathbf{E}$, number of grains per ear; $\mathbf{F}$, amount of water-soluble carbon (WSC) per stem at the end of the slow grain-fill period; G, percentage of stem storage capacity used at the end of the slow-fill period; and $\mathbf{H}$, HAD per grain. Triangles represent disease-free or fully treated crops, whereas circles represent crops affected by a severe epidemic. Note that tolerance increases with a decreased yield loss per unit HAD loss. The $\mathrm{x}$-axis is representative of the current genotypic variability for the trait in question as identified during a literature search.

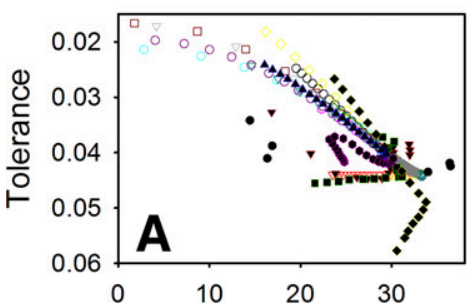

$\Delta \%$ sink filled

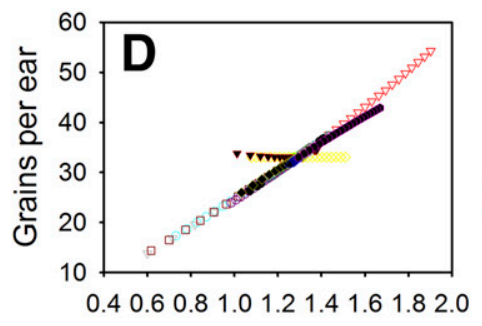

Total sink size

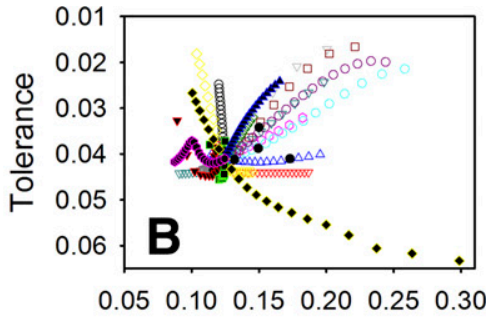

$\Delta$ Total sink size

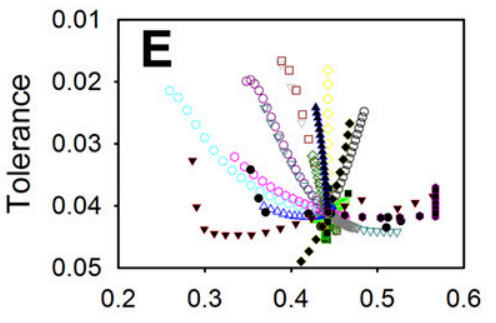

WSC at end of slow-fill period
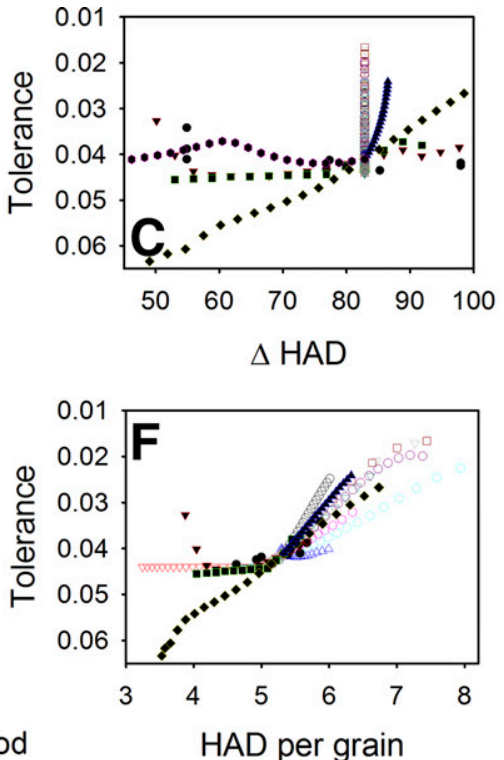

Fraction ear Max. grains ear ${ }^{-1}$ Fraction grain Max. grain volume Ext. coefficient Photosynthetic cap

CUE

Stem height

Stem diameter Stem thickness Storage efficiency Remobilisation rate Leaf specific weight Stem specific weight Root mass

- Pre-anthesis period

- Slow-fill period

- Rapid-fill period

- Canopy size

- Leaf distribution

- Shoot density

Fig. 4. Correlation plots for a selection of traits tested across their full trait range. A, Tolerance versus $\Delta \%$ sink filled; $\mathbf{B}$, tolerance versus $\Delta$ total sink filled; $\mathbf{C}$, tolerance versus $\Delta$ healthy area duration (HAD); D, grains per ear versus total sink size; $\mathbf{E}$, tolerance versus water-soluble carbon (WSC) reserves; and $\mathbf{F}$, tolerance versus HAD per grain. Closed and open symbols represent traits affected and not affected by HAD, respectively. That trait changes for which $\Delta \%$ sink filled $=$ 0 have been excluded from $\mathrm{A}, \mathrm{B}$, and $\mathrm{F}$. 
tolerance (Fig. 6D), (v) the maximum canopy GAI is positively correlated with tolerance (Fig. 6E), (vi) the light extinction coefficient is positively correlated with tolerance (Fig. 6F), and (vii) increased grain-fill periods, which lead to increased HAD, lead to increased tolerance (Fig. 6G), whereas the length of the preanthesis period has a more or less neutral effect on tolerance (Fig. $3 \mathrm{H}$ ).

Results from diverse parameter sets. The correlation between HAD per grain and tolerance for a wide range of parameter sets representing different cultivars is shown in Figure 7. Despite there being considerable scatter around the regression line, the linear regression reveals a highly significant regression slope $(P<$ 0.00001 ) with an overall $R^{2}$ of 0.48 .

\section{DISCUSSION}

The model analysis provides insights into the physiological traits that determine tolerance and helps to understand previous correlations of traits with tolerance reported in the literature. Relationships between high-level factors (sink size, \% sink filled, and HAD) and tolerance are discussed first and then we consider whether the analysis supports or refutes relationships between specific traits and tolerance reported previously in the literature.

What physiological crop traits determine tolerance? There has been no previous consideration in the literature of whether there might be consistent patterns of association between high-level factors and tolerance. Such patterns have been found here but there is little literature against which to compare the new findings summarized below. When a trait change has no effect on HAD (and $\Delta \%$ sink filled $\neq 0$ ), the $\Delta \%$ sink filled tends to be the main determinant of tolerance. The effect of $Z$. tritici on light interception and assimilation occurs predominantly postanthesis (due to its long latent period relative to the rate of leaf emergence), at which point the number of grains per ear (i.e., the main determinant of the total sink size) has already been set. Hence, it is understandable that $\Delta \%$ sink filled rather than $\Delta$ total sink size is the main determinant of tolerance.

When trait changes also affect $\Delta \mathrm{HAD}, \Delta \%$ sink filled still tends to be the main determinant of tolerance. Equation 1 shows that, if tolerance doesn't change much with changes in $\Delta \%$ sink filled, then either $\Delta$ total sink size has changed, too, or $\Delta \mathrm{HAD}$ has changed, or both. Increasing the preanthesis duration reduces \%sink filled in diseased but not nondiseased crops, reduces HAD in diseased but increases it in nondiseased crops, and increases total sink in both. Thus, both $\Delta \%$ sink filled and $\Delta \mathrm{HAD}$ are increased. The question then is: Why should an increase in the duration of the preanthesis period reduce HAD with disease but increase it without disease? A longer preanthesis period was assumed to be associated with an increased phyllochron length, which results in an increased HAD in the absence of disease. With the onset of the epidemic remaining constant, this means that the disease has longer to develop, leading to an increased postanthesis severity. This, in turn, leads to a reduced $\mathrm{HAD}$ in the presence of disease and, therefore, an increase in $\triangle \mathrm{HAD}$. Similar but less strong effects can be identified for the rapid grain-fill
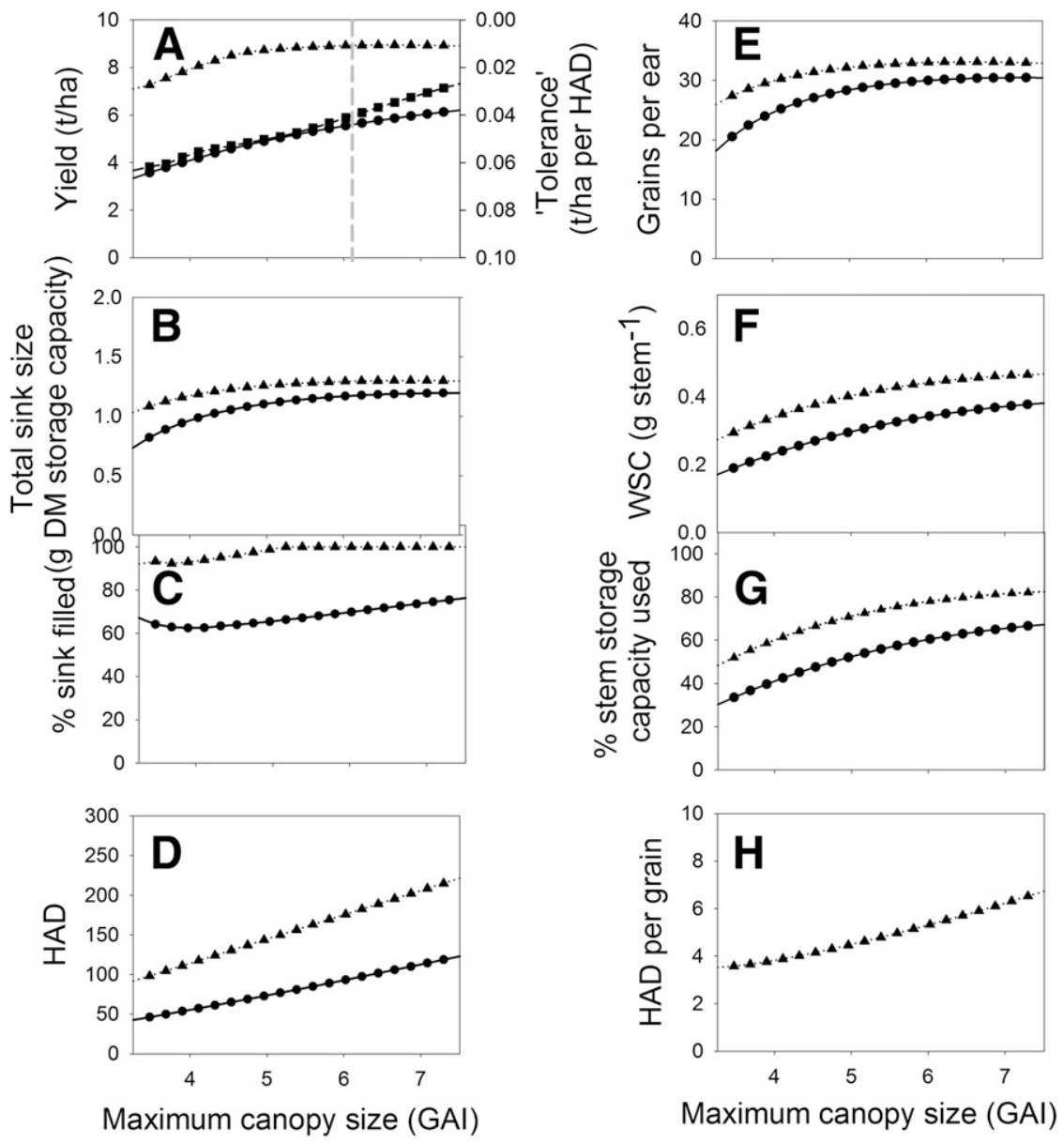

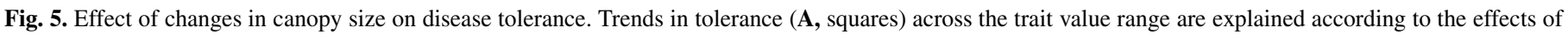

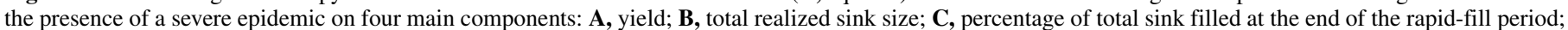

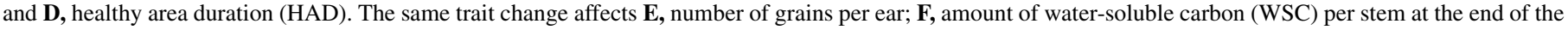

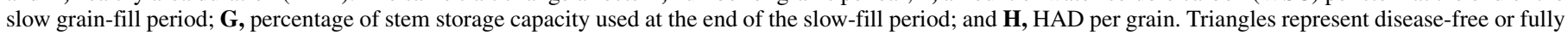

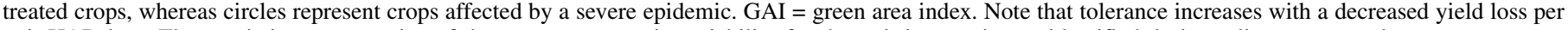
unit HAD loss. The $\mathrm{x}$-axis is representative of the current genotypic variability for the trait in question as identified during a literature search. 
period, due to the underlying assumption that an increased rapid-fill period is associated with increased leaf longevities for leaves 1 to 5 .

When yield is fully sink limited, we find that $\Delta$ total sink size and $\triangle \mathrm{HAD}$ control whether tolerance increases or decreases. This is counterintuitive because, if the sink is filled regardless of whether disease is present or not, one might expect the plant to be completely tolerant of disease. However, the definition of tolerance includes absolute (rather than percent) yield per unit HAD and, for those trait changes resulting in continually increasing sink limitation, $\Delta$ total sink size increases, leading to a decrease in tolerance.

Given that the main determinant of tolerance is the $\Delta \%$ sink filled, equation 2 can now help us to understand the effect of individual trait changes on tolerance. Changes in total sink size were shown to be predominantly affected by the number of grains per ear rather than the potential maximum grain size, which means that tolerance is closely related to the total assimilate available per grain. Assimilate for grain filling comes from remobilized WSC reserves and assimilate produced by leaf photosynthesis during the rapid-fill period. The contribution of WSC reserves in the simulations ranged from 26 to $66 \%$ of the total available assimilate. Hence, grain filling relies heavily on assimilation by green leaf and sheath tissues during the rapid-fill period. This results in a close correlation between HAD per grain and tolerance. Despite its large contribution to yield, there is no consistent positive correlation between percent yield from WSC reserves and tolerance that holds across a range of different traits or values (see below).

In the majority of cases ( 15 of the 21 traits studied), trait changes did not affect HAD and, given the discussion above, in these cases, an increased number of grains per ear decreases tolerance because it decreases HAD per grain. The number of grains per ear is determined by the amount of assimilate accumulated preanthesis and, therefore, it is straightforward to predict whether a change in trait value will affect the number of grains per ear and in what manner. For example, traits affecting assimilation rate (light extinction coefficient, $P_{\max }^{0}$, and CUE) are positively associated with preanthesis assimilate accumulation, leading to a larger number of grains per ear and reduced tolerance. Traits that determine the amount of structural biomass in the plant (stem height, stem diameter, fractional stem thickness, leaf specific weight, stem specific weight, and root mass) are all negatively associated with the amount of

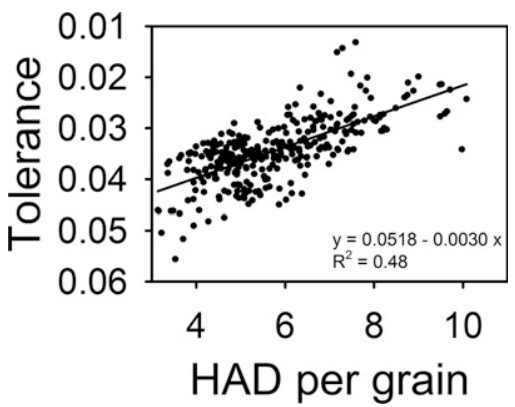

Fig. 7. Correlation between healthy area duration (HAD) per grain and tolerance for a large set of data sets. Note that, for each of these randomly selected parameter sets, the crop yield was $>9 \mathrm{t} / \mathrm{ha}$. The solid line represents the linear regression through the data points $(P<0.00001)$.

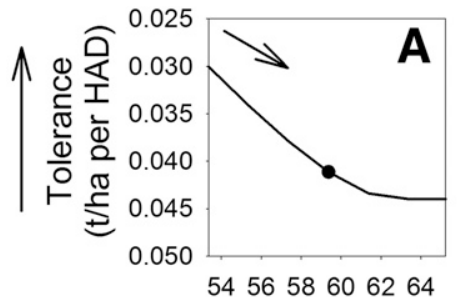

Max. number of grains per ear

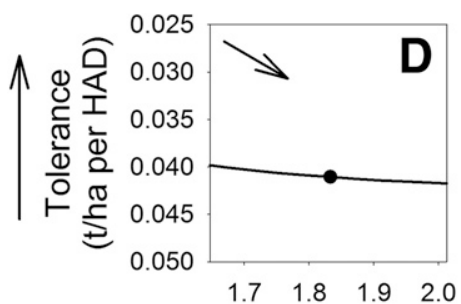

Max. photosynthetic capacity $\left(\mathrm{mol} \mathrm{CO} 2 \mathrm{~m}^{-2} \mathrm{~d}^{-1}\right)$

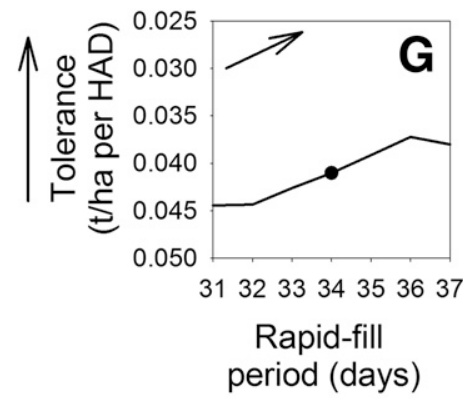

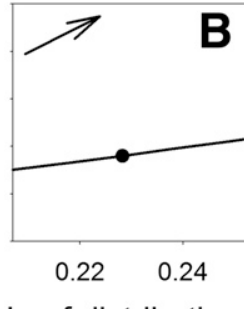
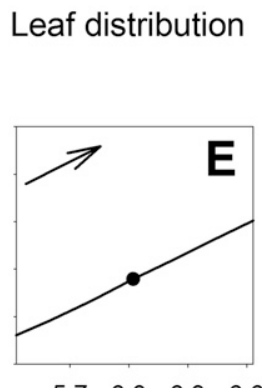

$\begin{array}{llll}5.7 & 6.0 & 6.3 & 6.6\end{array}$ size (GAl)

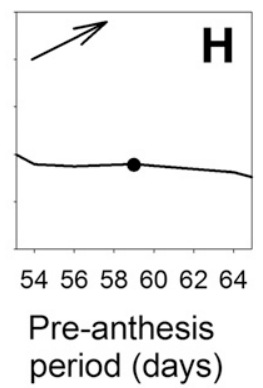

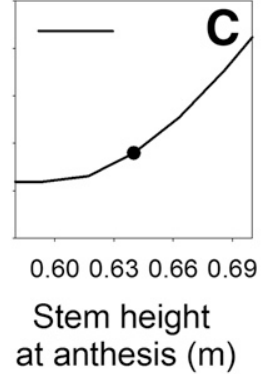

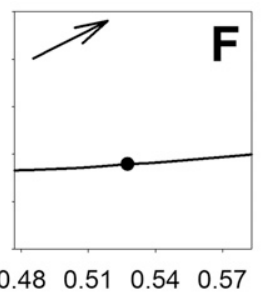

Light extinction coefficient

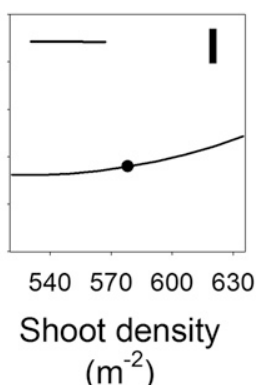

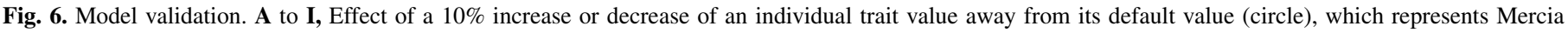

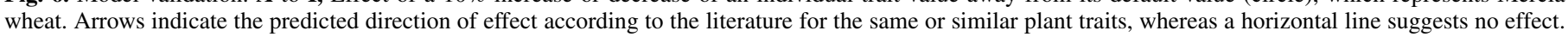

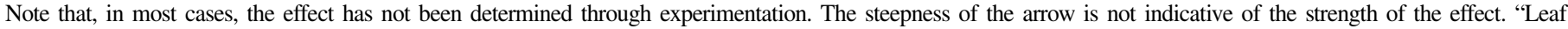

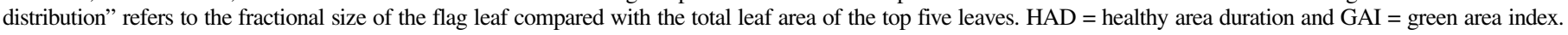


assimilate available for ear development, leading to a reduction in number of grains per ear and increased tolerance. Surprisingly, traits regulating stem storage dynamics (stem storage efficiency and stem reserves remobilization rate) did not affect the amount of assimilate available for ear development and, thus, had no effect on tolerance. We conclude that, in most cases, the number of grains per ear is an indicator of tolerance, making it possible to predict the effect of trait changes on tolerance.

This leaves the cases for which a trait change does affect HAD (i.e., the developmental period and canopy size traits: maximum canopy size, leaf area distribution, shoot density, preanthesis period, slow-fill period, and rapid-fill period). In all but one of these cases, increased HAD coincides with increased HAD per grain and, thus, increased tolerance because variation in these traits resulted in a stronger effect on HAD than on the number of grains per ear. The only exception is the duration of the preanthesis period, which has, as would be expected, a stronger effect on the number of grains per ear than on HAD postanthesis.

Results comparison against experimental data. The analysis was designed to check whether associations between traits and tolerance reported from field experiments could be explained mechanistically. Associations which cannot be readily explained are more likely to be spurious correlations. When varying the plant traits within the range of current genotypic variability, the model estimated a maximally achievable tolerance value $(0.0171)$ close to the maximum reported in the literature $(0.0141)$. Note that the values represent the slope of the HAD versus yield relationship and that smaller values, therefore, represent increased tolerance. The minimum tolerance values estimated by the model lie at approximately 0.04 , which compares well with the minimum of 0.036 reported within experimental studies (Foulkes et al. 2006; Parker et al. 2004). However, when varying CUE, we found tolerance values up to 0.063 (indicating extremely poor tolerance) but trait changes leading to extremely low tolerance also went paired with extremely low disease-free yield. Such wheat lines would not be selected as elite cultivars or be included in field experiments, where the aim is to increase tolerance while maintaining high yield.

The effects of changes in traits on tolerance is largely in agreement with the trends derived experimentally or suggested within the literature. Most strikingly, Foulkes et al. (2006) found a significant negative correlation between grains per square meter and tolerance. This finding is in close agreement with our conclusion that, in the absence of an effect on HAD, the key determinant of tolerance is the number of grains per ear.

The model results suggest that traits that increase the plant's assimilation rate will result in a reduction in tolerance. Parker et al. (2004) compared the disease tolerance levels of plants with and without the 1BL/1RS translocation and found a negative correlation between the presence of the translocation and tolerance. This translocation has been associated with a possible increase in radiation use efficiency (RUE) (Foulkes et al. 2006) and, thus, an increased assimilation rate. This matches our prediction that tolerance is negatively associated with the plant's assimilation rate.

Bingham et al. (2009) inferred that larger extinction coefficients should lead to increased tolerance through greater interception of solar radiation per unit green area by leaves in the upper canopy. This is in disagreement with our finding although, across the U.K. genotypic variability in light extinction coefficient, the effect on tolerance was estimated to be negligible.

The only experimental study to assess the effect on tolerance of traits that determine the amount of structural biomass is the field study by Foulkes et al. (2006). They found that the presence of Rht-D1b alleles (associated with semidwarfing) did not have a significant effect on tolerance. Their initial reasoning was that this is due to the Rht allele not affecting WSC reserves but later argued that WSC might not affect tolerance anyway. This case presents the main discrepancy between model and data, because our analysis suggested that trait changes that increase the amount of structural biomass are positively correlated with tolerance. However, dwarfing genes have a number of pleiotropic effects such as increased ear fertility (Flintham et al. 1997), increased light extinction coefficients (Miralles and Slafer 2007), and shorter leaves (Calderini et al. 1996), with potentially opposing effects on tolerance. It may be that these pleiotropic effects cause the previously reported absence of changes in tolerance with dwarfing.

Previous work has suggested that increased WSC accumulation will increase disease tolerance, regardless of the overall storage capacity (Bingham et al. 2009; Blum 1998; Ehdaie et al. 2006). The only study directly testing this hypothesis found that WSC reserves were negatively correlated with tolerance (Foulkes et al. 2006). The analysis reported here found that changes to plant traits that increase WSC reserves stored per shoot can either increase or decrease tolerance. There are two possible ways in which WSC reserves are related to tolerance. The first is in the case of trait changes where there is a direct trade-off between WSC reserves and number of grains per ear. The only trait for which this is the case is the fraction ear versus stem reserves investment. Yet, even in this case it is HAD per grain that determines tolerance. The second is in the case of trait changes that lead to stem storage limitation during the slow-fill period. The only trait for which this is the case is the shoot density. Increased shoot densities lead to both an increased HAD and a decreased number of grains per ear and, hence, an increased HAD per grain, suggesting that tolerance will increase with increased shoot densities. However, an increased shoot density will also lead to an increased number of grains per square meter, suggesting that overall HAD per grain might not increase much with an increased shoot density, which is supported by the weak positive effect of shoot density on tolerance (with shoot density changes modeled by changes in ears per square meter). In this case, it is WSC that determines $\Delta \%$ sink filled and, hence, tolerance.

Finally, our results reveal that trait changes that increase HAD (with the exception of an increased preanthesis period) coincide with an increased HAD per grain and increased tolerance. The literature supports this finding. For example, Foulkes et al. (2006) found a positive correlation between flag leaf area and tolerance. Additionally, Bingham et al. (2009) infer that crops with large canopies might be more tolerant to disease through an increased ability to maintain radiation interception per unit green area loss to disease. Similarly, for doubled-haploid progeny from a cross between U.K. 'Cadenza' and 'Lynx' wheat, tolerance was found to be associated with high postanthesis HAD (Paveley et al. 2008).

The model study has helped us to understand the processes involved in tolerance and has either supported, explained further, or dispelled previously reported associations between certain traits and tolerance. Some findings remain unclear, with the main discrepancy being between experimental data and model predictions regarding the effect of Rht-D1b alleles (as a proxy for changes in stem height) on tolerance.

Results from diverse parameter sets. The results presented in Figures 2 to 6 are all based on variations of single-parameter values away from the benchmark Mercia parameter set. Our main conclusion based on these results is that HAD per grain is a good predictor of tolerance. The main question now is whether this conclusion is only valid for cultivars with parameter values very similar to Mercia or whether our conclusion would also hold for a wider range of cultivars. Running the results for a large range of diverse parameter sets (representing a range of different cultivars and potential within cultivar variability) has shown that, despite there being quite some scatter around the tolerance and HAD per grain regression line, the relationship is highly significant, which generalizes our main finding beyond Mercia.

Model assumptions and their potential implications. Tolerance is the result of the complex and nonlinear interactions of light capture, assimilate production and allocation, leaf and stem growth, ear development, and grain filling. Currently, there is no model available that dynamically simulates the dynamics of the determination of ear 
size, the determination of grain number, and potential grain size as a function of assimilate availability, and then accurately models the final grain filling. Therefore, we have developed a model that incorporates all these processes. This implies that the model is complex but, even in a complex model, some simplifying assumptions are made. Here, we discuss the possible consequences of our assumptions.

Because of the limited data describing what drives the partitioning of assimilates between ear growth and accumulating stem reserves, this part of the model was necessarily descriptive rather than mechanistic. It was assumed that the fraction of available assimilate that is partitioned to the ear is a function of the total biomass accumulated preanthesis such that, when there is little biomass to invest, a proportionally larger fraction is allocated to the ear; whereas, when there is a lot of biomass to invest, a proportionally larger fraction is allocated to the stem reserves. When this dynamic partitioning fraction was replaced by a constant fraction, the results remained qualitatively unchanged (results not shown).

We have assumed the environment to be constant. This is because one of the aims was to provide guidance to breeders on physiological traits affecting tolerance. Disentangling the interacting effects of individual traits on source and sink capacities and tolerance is complex even under a constant environment (E); thus, in this study, we consider the genetic (G) effects only and, for now, not the G-E interactions. However, the model has the capacity for investigating effects of environmental conditions (e.g., temperature and radiation) and the timing of disease epidemics on tolerance.

Foliar pathogens can modify the growth of plants through multiple injury mechanisms (Boote et al. 1983; Gaunt 1995). The effects of injury on yield depend on the timing of the disease epidemic in relation to the phenology of the crop and the extent to which plants can compensate for the injury through adjustments in physiology and morphology (Bingham et al. 2009; Boote et al. 1983; Gaunt 1995; Ney et al. 2013). Late epidemics provide fewer opportunities for morphological adjustments to take place (Bingham et al. 2009; Gaunt 1995). In wheat, the maximum leaf number and size is set by flag emergence and, with the exception of occasional late tillering, the number of ears and grains is determined by anthesis.

In this study, we have parameterized the model using data on $Z$. tritici. We have assumed that the contribution to tolerance of compensatory physiological and morphological adjustments (Bingham et al. 2009; Ney et al. 2013) in this pathosystem is small. In temperate climates, epidemics of Septoria tritici blotch tend to develop late, with disease reducing yield through effects on average grain weight and, to a lesser extent, grain number per ear rather than the number of ears (Forrer and Zadoks 1983; Robert et al. 2004). Epidemics are generally too late to induce differences in leaf size and number (Robert et al. 2004). Robert et al. (2006) reported that, within $Z$. tritici-infected leaves, reductions in net photosynthesis were caused by the replacement of green tissue by necrotic lesions. In comparison with some other pathogens, reductions in net photosynthesis in asymptomatic tissue surrounding the visible lesions were small. Moreover, there is little evidence of compensatory adjustments in the photosynthetic rate or growth of noninfected leaves on wheat infected with Z tritici (Bingham et al. 2009; Ney et al. 2013; Zuckerman et al. 1997). These observations are consistent with reports that Septoria tritici blotch has little effect on the RUE of field-grown wheat (Serrago et al. 2009). Other foliar diseases share similar patterns of disease progress curves, because the timing of disease on each leaf layer is determined largely by leaf emergence (Paveley et al. 2000). Therefore, the methods used should be applicable to other foliar diseases of wheat. However, the model would need specific parametrization to account for differences between pathogens on photosynthetic activity beyond visible disease lesions (Rolfe and Scholes 2010; Scholes and Rolfe 2009) and on potential compensatory adjustments in growth and photosynthetic activity (Ney et al. 2013).

Traits that confer tolerance in wheat might not do so in others crops. For example, barley is more sink limited than wheat (Bingham et al. 2007a,b), and early treatment of foliar disease often results in increases in sink components (shoots per square meter and grains per ear). Therefore, it would be inappropriate to extrapolate our results directly to other crop species. After suitable parameterization, the model can be used to simulate and investigate source-sink relations and their influence on disease tolerance in other cereal crops. As such, it promises to be a valuable tool for guiding the improvement of tolerance in a range of species.

\section{ACKNOWLEDGMENTS}

Funding through the U.K. Department for Environment, Food and Rural Affairs is gratefully acknowledged. Rothamsted Research receives support from the Biotechnology and Biological Sciences Research Council of the United Kingdom. Scotland's Rural College receives financial support from the Scottish Government's Rural and Environmental Science and Analytic Services division.

\section{LITERATURE CITED}

Bancal, P. 2008. Positive contribution of stem growth to grain number per spike in wheat. Field Crops Res. 105:27-39.

Beasse, C., Ney, B., and Tivoli, B. 2000. A simple model of pea (Pisum sativum) growth affected by Mycosphaerella pinodes. Plant Pathol. 49: 187-200

Bingham, I. J., Blake, J., Foulkes, M. J., and Spink, J. 2007a. Is barley yield in the UK sink limited? I. Post-anthesis radiation interception, radiation-use efficiency and source-sink balance. Field Crops Res. 101:198-211.

Bingham, I. J., Blake, J., Foulkes, M. J., and Spink, J. 2007b. Is barley yield in the UK sink limited? II. Factors affecting potential grain size. Field Crops Res. 101:212-220.

Bingham, I. J., Karley, A. J., White, P. J., Thomas, W. T. B., and Russell, J. R. 2012. Analysis of improvements in nitrogen use efficiency associated with 75 years of spring barley breeding. Eur. J. Agron. 42:49-58.

Bingham, I. J., and Topp, C. F. E. 2009. Potential contribution of selected canopy traits to the tolerance of foliar disease by spring barley. Plant Pathol. 58:1010-1020.

Bingham, I. J., Walters, D. R., Foulkes, M. J., and Paveley, N. D. 2009. Crop traits and tolerance of wheat and barley to foliar disease. Ann. Appl. Biol. 154:159-173.

Blum, A. 1998. Improving wheat grain filling under stress by stem reserve mobilisation. Euphytica 100:77-83.

Boote, K. J., Jones, J. W., Mishoe, J. W., and Berger, R. D. 1983. Coupling pests to crop growth simulations to predict yield reductions. Phytopathology 73:1581-1587.

Calderini, D. F., Miralles, D. J., and Sadras, V. O. 1996. Appearance and growth of individual leaves as affected by semidwarfism in isogenic lines of wheat. Ann. Bot. (Lond.) 77:583-589.

Carretero, R., Serrago, R. A., Bancal, M.-O., Perello, A. E., and Miralles, D. J. 2010. Absorbed radiation and radiation use efficiency as affected by foliar diseases in relation to their vertical position into the canopy in wheat. Field Crops Res. 116:184-195.

Clarke, S., Sylvester-Bradley, R., Foulkes, J., Ginsburg, D., Gaju, O., Wemer, P. J., Flatman, E., and Smith-Reeve, L. 2012. Adapting wheat to global warming. HGCA Rep. No. 496. Home Grown Cereals Authority, London.

Ehdaie, B., Alloush, G. A., Madore, M. A., and Waines, J. G. 2006. Genotypic variation for stem reserves and mobilization in wheat: I. Postanthesis changes in internode dry matter. Crop Sci. 46:735-746.

Flintham, J. E., Börner, A., Worland, A. J., and Gale, M. D. 1997. Optimizing wheat grain yield: Effects of $R h t$ (gibberellin-insensitive) dwarfing genes. J. Agric. Sci. 128:11-25.

Forrer, H. R., and Zadoks, J. C. 1983. Yield reduction in relation to leaf necrosis caused by Septoria tritici. Neth. J. Plant Pathol. 89:87-98.

Foulkes, M. J., Paveley, N. D., Worland, A., Welham, S. J., Thomas, J., and Snape, J. W. 2006. Major genetic changes in wheat with potential to affect disease tolerance. Phytopathology 96:680-688.

Gaunt, R. E. 1995. The relationship between plant disease severity and yield. Annu. Rev. Phytopathol. 33:119-144.

González, F. G., Miralles, D. J., and Slafer, G. A. 2011. Wheat floret survival as related to pre-anthesis spike growth. J. Exp. Bot. 62:4889-4901.

Hasan, A. K., Herrera, J., Lizana, C., and Calderini, D. F. 2011. Carpel weight, grain length and stabilized grain water content are physiological drivers of grain weight determination of wheat. Field Crops Res. 123: 241-247.

Johnson, I. R., and Thornley, J. H. M. 1984. A model of instantaneous and daily canopy photosynthesis. J. Theor. Biol. 107:531-545.

Madden, L. V., and Nutter, F. W., Jr. 1995. Modeling crop losses at the field scale. Can. J. Plant Pathol. 17:124-137. 
Miralles, D. J., and Slafer, G. A. 2007. Sink limitations to yield in wheat: How could it be reduced? J. Agric. Sci. 145:139-149.

Ney, B., Bancal, M.-O., Bancal, P., Bingham, I. J., Foulkes, J., Gouache, D., and Smith, J. 2013. Crop architecture and crop tolerance to fungal diseases and insect herbivory. Mechanisms to limit crop losses. Eur. J. Plant Pathol. 135:561-580.

Parker, S. R., Welham, S., Paveley, N. D., Foulkes, J., and Scott, R. K. 2004. Tolerance of Septoria leaf blotch in winter wheat. Plant Pathol. 53:1-10.

Paveley, N., Blake, J., Gladders, P., and Cockerell, V. 2012. HGCA Wheat Disease Management Guide 2012. Home Grown Cereals Authority, London.

Paveley, N. D., Lockley, D., Vaughan, T. B., Thomas, J., and Schmidt, K. 2000. Predicting effective fungicide doses through observation of leaf emergence. Plant Pathol. 49:748-766.

Paveley, N. D., Smith, J. S., and Foulkes, J. 2008. Traits for reduced fungicide dependence. Pages 35-47 in: BSPP Presidential Meeting. G. Jellis and C. Edwards, eds. Queen Mary, University of London.

Robert, C., Bancal, M.-O., Lannou, C., and Ney, B. 2006. Quantification of the effects of Septoria tritici blotch on wheat leaf gas exchange with respect to lesion age, leaf number, and leaf nitrogen status. J. Exp. Bot. 57:225-234.

Robert, C., Bancal, M.-O., Nicolas, P., Lannou, C., and Ney, B. 2004. Analysis and modelling of effects of leaf rust and Septoria tritici blotch on wheat growth. J. Exp. Bot. 55:1079-1094.

Rolfe, S. A., and Scholes, J. D. 2010. Chlorophyll fluorescence imaging of plant-pathogen interactions. Protoplasma 247:163-175.

Schnyder, H. 1993. The role of carbohydrate storage and redistribution in the source-sink relations of wheat and barley during grain filling-A review. New Phytol. 123:233-245.

Scholes, J. D., and Rolfe, S. A. 2009. Chlorophyll fluorescence imaging as tool for understanding the impact of fungal diseases on plant performance: A phenomics perspective. Funct. Plant Biol. 36:880-892.

Serrago, R. A., Carretero, R., Bancal, M.-O., and Miralles, D. J. 2009. Foliar diseases affect the eco-physiological attributes linked with yield and biomass in wheat (Triticum aestivum L.). Eur. J. Agron. 31:195-203.

Sinclair, T. R., and Jamieson, P. D. 2006. Grain number, wheat yield, and bottling beer: An analysis. Field Crops Res. 98:60-67.

Singh, B. K., and Jenner, C. F. 1984. Factors controlling endosperm cell number and grain dry weight in wheat: Effects of shading on intact plants and of variation in nutritional supply to detached, cultured ears. Aust. J. Plant Physiol. 11:151-163.

Spink, J., Foulkes, J. M., Gay, A., Bryson, R., Berry, P., Sylvester-Bradley, R., Semere, T., Clare, R. W., Scott, R. K., Kettlewell, P. S., and Russell, G. 2000a. Reducing winter wheat production costs through crop intelligence information on variety and sowing date, rotational position, and canopy management in relation to drought and disease control. HGCA Proj. Rep. No. 235. Home Grown Cereals Authority, London.

Spink, J. H., Berry, P., Theobald, C., Sparkes, D., Wade, A., and Roberts, A. 2004. The effect of location and management on target drilling rate for winter wheat. HGCA Proj. Rep. No. 361. Home Grown Cereals Authority, London.

Spink, J. H., Whaley, J., Semere, T., Wade, A., Sparkes, D., and Foulkes, J. 2000b. Prediction of optimum plant population in winter wheat. HGCA Proj. Rep. No. 234. Home Grown Cereals Authority, London.

Sylvester-Bradley, R. 1998a. Assessments of wheat growth to support its production and improvement. Volume I: The wheat growth digest. Proj. Rep. 151. Home Grown Cereals Authority, London.

Sylvester-Bradley, R. 1998b. Assessments of wheat growth to support its production and improvement. Volume II: How to run a reference crop. Proj. Rep. 151. Home Grown Cereals Authority, London.

Sylvester-Bradley, R. 1998c. Assessments of wheat growth to support its production and improvement. Volume III: The dataset. Proj. Rep. 151. Home Grown Cereals Authority, London.

Sylvester-Bradley, R., Berry, P., Blake, J., Kindred, D., Spink, J., Bingham, I. J., McVittie, J., and Foulkes, J. 2008. The Wheat Growth Guide. Home Grown Cereals Authority, London.

Thornley, J. H. M., and Johnson, I. R. 1990. Plant and Crop Modelling: A Mathematical Approach to Plant and Crop Physiology. Clarendon Press, Oxford.

Waggoner, P. E., and Berger, R. D. 1987. Defoliation, disease, and growth. Phytopathology 77:393-398.

Xie, Q., Mayes, S., and Sparkes, D. L. 2015. Carpel size, grain filling, and morphology determine individual grain weight in wheat. J. Exp. Bot. 66: 6715-6730.

Zadoks, J. C., Chang, T. T., and Konzak, C. F. 1974. A decimal code for the growth stages of cereals. Weed Res. 14:415-421.

Zuckerman, E., Eshel, A., and Eyal, Z. 1997. Physiological aspects related to tolerance of spring wheat cultivars to Septoria tritici blotch. Phytopathology 87:60-65. 